\title{
Pacientų, gydomų inhaliuojamojo gliukokortikoido ir ilgai veikiančio beta 2 agonisto sudètiniu vaistu, astmos kontrolè
}

\section{Realiụ sạlygụ tyrimas, skirtas palyginti dozuotus miltelinius inhaliatorius su dozuotu aerozoliniu itin smulkių dalelių inhaliatoriumi}

\author{
Edita Gasiūnienè \\ LSMU MA Pulmonologijos ir imunologijos klinika
}

Reikšminiai žodžiai: astmos kontrolè, inhaliatorius, beklometazono propionatas, formoterolis, itin smulkios dalelès.

Santrauka. Straipsnyje aptariami rezultatai realių gyvenimo sąlygų tyrimo, skirto palyginti astmos kontrolę gydant arba dozuotu milteliniu, arba dozuotu aerozoliniu itin smulkių dalelių inhaliuojamojo gliukokortikoido ir ilgai veikiančio beta 2 agonisto sudètiniu vaistu viename inhaliatoriuje.

\section{IVADAS}

Astma veikia pasaulio visuomenès sveikatą dèl itin didelio paplitimo bendroje populiacijoje (nuo 1 proc. iki 18 proc. gyventojų įvairiose šalyse). Keletas naujausių tyrimų rodo, kad poveikis visuomenès sveikatai itin ryškus, nes visiškai suvaldyti ligą dabar turimomis terapinėmis priemonėmis yra sunku [1,2]. Pasiekti ir išlaikyti astmos kontrolę - pagrindinis astmos gydymo tikslas. Remiantis GINA (angl. Global Initiative for Asthma) 2009 m. rekomendacijomis, astmos kontrolè gali būti vertinama atsižvelgiant i i ivairius parametrus, ịskaitant dienos simptomus, naktinius prabudimus, skubiosios pagalbos vaistu poreikị, fizinio krūvio ribotumą bei plaučių funkciją [2]. Atsitiktinių imčių klinikiniai tyrimai rodo, kad dabartinès astmos gydymo priemonès yra tinkamos astmos kontrolei užtikrinti [3]. Deja, atsitiktinių imčiu klinikiniai tyrimai, kuriais vertinamas vaistu efektyvumas, dažnai neatitinka realaus gyvenimo sąlygų, kuriomis astmos kontrole - vis dar neigyvendintas siekis daugumai pacientu $[1,4]$. Nepaisant gydymo galimybiu ivvairovès ir periodiškai nuo $1995 \mathrm{~m}$. atnaujinamu GINA rekomendacijų, akivaizdu, kad astmos kontrolè nèra optimali $[1,5]$.

Atsitiktinių imčiu klinikiniai tyrimai atliekami pagal griežtai kontroliuojamus parametrus atrinktoje pacientų grupejje. Šiomis kontroliuojamomis sąlygomis paprastai tikrinama jkvejpimo technika, jai teikiama ypatinga reikšmé, pabrèžiama nurodymų laikymosi 
1 lentelè. Astmos kontrolès klausimynas

1. Ar per paskutinę savaitę buvo astmos simptomų (dusulys, švokštimas) dienos metu?

\begin{tabular}{ll}
\hline a. Ne & 0 balų \\
b. Taip, bet ne daugiau kaip 2 kartus per savaitę & 1 balas \\
c. Taip, daugiau nei 2 kartus per savaitę & 5 balai
\end{tabular}

2. Ar per paskutinę savaitę buvo simptomų nakties metu ARBA ar jūs prabudote naktị dèl astmos sukeltų simptomų?

\begin{tabular}{ll} 
a. Ne & 0 balú \\
b. Taip, bet nesu tikras, ar tai buvo astma & 1 balas \\
c. Taip & 5 balai \\
\hline
\end{tabular}

3. Ar jautėte, kad astma riboja fizinị krūvị per paskutinę savaitę?

a. $\mathrm{Ne} \quad 0$ balu

b. Taip, bet tik intensyvaus fizinio krūvio metu 1 balas

c. Taip, normalaus fizinio krūvio metu $\quad 5$ balai

4. Kaip dažnai vartojote skubiosios pagalbos vaistus (Ventolin/ Berotec/Berodual/Salbutamol/Atrovent/Bricanyl/Symbicort) per paskutinę savaitę?

\begin{tabular}{ll}
\hline a. Nevartojau & 0 balų \\
b. Ne daugiau kaip 2 kartus per savaitę & 1 balas \\
c. Daugiau kaip 2 kartus per savaitę & 5 balai
\end{tabular}

5. Ar buvo astmos paūmèjimas, kurị reikejjo gydyti skubiosios pagalbos skyriuje ar stacionare, nuo tada, kai palaikomajam gydymui vartojate ši vaistą?

\begin{tabular}{ll} 
a. Ne & 0 baluc \\
c. Taip & 5 balai \\
\hline \multicolumn{2}{c}{ Balų suma: }
\end{tabular}

Kontroliuojama astma $-0-4$ balai

Iš dalies kontroliuojama astma - 5-14 balu

Nekontroliuojama astma - daugiau kaip 14 balu

svarba. Tokio griežto taisyklių laikymosi ne visada galima tikètis realiame gyvenime. Tarptautinè pirminès sveikatos priežiūros respiratologų grupè nagrinejjo veiksnius, lemiančius nepakankamą ligos kontrolę [6]. Išskirtos šios pagrindinès priežastys: neteisinga diagnozè, rūkymas, gretutinès ligos, individualus atsakas i gydymą, blogas nurodymų laikymasis, netaisyklinga ikvėpimo technika.

Inhaliuojamųjų gliukokortikoidų (IGK) bei ilgai veikiančių beta 2 agonistų (IVBA) sudètiniams vaistams ikkvèpti naudojami dozuoti milteliniai (DMI) bei dozuoti aerozoliniai (DAI) inhaliatoriai. Žinoma, kad parinkti kiekvienam pacientui tinkamą inhaliatorių yra labai svarbu, nes, vaisto ikvėpus netinkamai, i kvėpavimo takus gali patekti nepakankamas kiekis vaisto bei sumažèti gydymo efektyvumas [7, 8]. Atsitiktinių imčių klinikinių tyrimų, lyginusių to paties vaisto įkvèpimą iš skirtingų inhaliatorių, metaanalizė rodo, kad vaisto veiksmingumas naudojant DMI ar DAI statistiškai reikšmingai nesiskyrè $[9,10]$, tačiau nurodoma, jog naudojant DAI padaroma mažiau klaidų ịkvepiant [11-13].

Neseniai sukurtas naujas beklometazono ir formoterolio $(\mathrm{BDP} / \mathrm{F})$ sudetinis vaistas viename inhaliatoriuje, kuriam būdingos itin smulkios dalelès [14], lemiančios geresnị vaisto kaupimąsi plaučiuose, tolygų uždegimo ir obstrukcijos gydymą visame bronchų me- dyje [15]. BDP/F itin smulkių dalelių formulè sukuria ilgiau išsilaikantị aerozolio debesẻlį, todèl paprasčiau suderinti inhaliatoriaus paspaudimą su ikvèpimu, ir tai palengvina vaisto įkvépimo procesą [17]. Teigiama, kad, naudojant itin smulkių dalelių DAI, ikkvépimo technika turi mažiau reikšmès nei naudojant kitus DAI, nes vaisto sankaupa plaučiuose mažiau priklauso nuo ikvepiamo oro srauto greičio bei koordinacijos [18, 19]. Dar daugiau, greitas bronchų išsiplètimas gali pagerinti nurodymų laikymąsi bei gydymo efektyvumą [20].

Aptariamo klinikinio stebejjimo tyrimo tikslas buvo ivertinti nuolatine vidutinio sunkumo bei sunkia astma sergančių pacientų ligos kontrolę ir palyginti vaistų efektyvumą realiomis gyvenimo sąlygomis gydant $\mathrm{BDP} / \mathrm{F}$ itin smulkių dalelių DAI ir kitais IGK/IVBA DMI inhaliatoriais (FP/S arba BUD/F).

\section{METODAI}

\section{Klinikinio tyrimo modelis ir pacientai}

Šis realių gyvenimo sąlygu tyrimas pradètas $2008 \mathrm{~m}$. pavasari ir truko keturis ménesius. I ji buvo itraukti Semelveiso universiteto (Budapeštas, Vengrija) pulmonologijos skyriaus vyresni nei $18 \mathrm{~m}$. amžiaus pacientai, sergantys persistuojančia/nuolatine vidutinio sunkumo ar sunkia astma, kuri buvo nustatyta gydytojo pulmonologo ne mažiau kaip 6 mèn. iki įtraukimo i tyrimą ir paskutines 6 savaites nebuvo astmos paūmejjimo epizodų. Palaikomajam gydymui pacientai vartojo IGK ir IVBA derinit, vaistai nebuvo keisti paskutines 4 savaites iki įtraukimo i tyrimą. I klinikini tyrimą nebuvo įtraukiami pacientai, sergantys kitomis lètinėmis ligomis (išskyrus lètinị rinitą), smarkiai nutukę ar per paskutines 6 savaites iki ịtraukimo ị tyrimą susirgę ūmine liga. Itraukiant pacientus it rūkymą ir kitus žalingus ipročius nebuvo atsižvelgiama. Astmos sunkumas nustatytas ligos diagnozavimo dieną ir vertintas gydančiojo gydytojo.

Astmos kontrole buvo vertinama pagal pacientu užpildytus klausimynus (1 lentelè), paruoštus remiantis GINA rekomendacijomis. Laikyta, kad astma kontroliuojama gerai, jei surinkta $\leq 4$ balų, o nekontroliuojama - jei $\geq 14$ balų, tarpinis balų skaičius rodè iš dalies kontroliuojamą astmą. Pacientai užpildydavo klausimynus kiekvieno apsilankymo metu. Norint nustatyti, ar ittakos astmos kontrolei gali turèti kiti veiksniai, informacija surinkta iš pacientų medicinos dokumentų: diagnozès nustatymo data, diagnozè, rūkymo, alergijos istorija, astmos nuolatinis gydymas bei simptomų malšinimas. Plaučių funkcijos rodikliai matuoti per pacientų reguliarius apsilankymus (palaikomojo astmos gydymo metu): forsuotas iškvėpimo tūris per 1 sekundę $\left(\mathrm{FEV}_{1}\right)$, didžiausias iškvepiamo oro srovès greitis (PEF), maksimalus vidutinis iškvèpimo srovès greitis tarp 25 proc. ir 75 proc. FVC (FEF 25-75 proc.), maksimalus iškvèpimo greitis (MEF) 25 proc. ir MEF 75 proc. 


\section{Rūkančiųjų pogrupis}

35 proc. pacientų, ịtrauktų i tyrimą, buvo rūkantys ar anksčiau rūkę, vidutinis rūkymo intensyvumas - 19,0 \pm 3,6 pakmečiai. Nors rūkymo intensyvumas neturèjo itakos IGK dozei, jis gerokai padidino nekontroliuojamos astmos dažnumą, palyginti su niekada nerūkiusiais pacientais (11 proc., palyginti su 23 proc., $\mathrm{p}<0,05$ ).

\section{REZULTATU APTARIMAS}

Tyrime dalyvavo 111 pacientu ( 81 moteris ir 30 vyrų), kurie buvo suskirstyti $\mathfrak{i}$ dvi grupes pagal tai, kokio tipo inhaliatoriu naudojo - dozuotą aerozolini (DAI) ar dozuotą milteliní (DMI). Pacientu astmos kontrolè abiejose tyrimo grupèse ir visoje tyrimo populiacijoje matyti 2 lentelèje ir 1 paveiksle. Lyginant dvieju tipu inhaliatorius, nustatyta, kad DAI grupeje kontroliuojamos astmos dažnumas buvo didesnis nei DMI grupeje ( $\mathrm{p}=0,031$; Chi kvadratas).

Vidutinis astmos kontrolès balas buvo statistiškai reikšmingai mažesnis itin smulkių dalelių DAI grupeje, palyginti su dideliu dalelių DMI grupe $(\mathrm{p}=0,016)$. Tai leidžia manyti, kad astma geriau kontroliuota gydant pacientus BDP/F itin smulkių daleliụ DAI. Nagrinèjant atskirus astmos kontrolès kriterijus, nustatyta, kad vidutiniai dienos simptomu balai buvo statistiškai reikšmingai mažesni itin smulkių dalelių DAI grupeje, palyginti su dideliuc dalelių DMI grupe $(\mathrm{p}=0,012)$, statistiškai reikšmingai mažiau suvartota ir skubiosios pagalbos vaistu $(\mathrm{p}=0,025)$. Balai, atspindintys naktinius simptomus ir fizinio aktyvumo ribotumą, tarp grupių statistiškai reikšmingai nesiskyrè.

Pažymètina, kad vidutinė paros IGK dozė buvo statistiškai reikšmingai mažesnè naudojant $\mathrm{BDP} / \mathrm{F}$ itin smulkių daleliu DAI. Taigi šioje grupèje astmos kontrolè pasiekta vartojant mažiau IGK ( $\mathrm{p}<0,001 ; 2$ pav.). Jokių statistiškai reikšmingų spirometrijos rodikliu skirtumų tarp gydymo grupiu nebuvo nustatyta.

Kaip ir minèta, astmos kontrolès lygis nustatytas naudojant šiam tyrimui pritaikytą klausimyna pagal dabartines GINA rekomendacijas. Pagal GINA rekomenduojamą astmos kontrolès vertinimą (kuris apima ir plaučių funkciją) 38,74 proc. pacientų astma buvo gerai kontroliuojama, 38,74 proc. - iš dalies kontroliuojama ir 22,52 proc. - nekontroliuojama.

\section{APTARIMAS}

Tai pirmasis realiu sąlygu tyrimas, skirtas palyginti BDP/F itin smulkių dalelių DAI klinikinị efektą su kitais sudètiniu vaistu inhaliatoriais. Ankstesniu klinikinių atsitiktinių imčių tyrimais nenustatyta skirtumų tarp BDP/F itin smulkių dalelių DAI ir BUD/F ar FP/S didelių dalelių DMI vertinant plaučių funkciją, skubiosios pagalbos vaistų vartojimą, paūmèjimų skaičiuc ir saugumą [22, 23]. Tačiau šie tyrimai neatspindèjo kasdienio iprastinio vaisto vartojimo, kai nurodymu laikymasis arba paciento gebejimas naudoti inhaliato-
2 lentelè. Astmos kontrolès dažnumas pacientų grupèse

\begin{tabular}{llll}
\hline & $\begin{array}{l}\text { BDP/F itin } \\
\text { smulkių daleliuc } \\
\text { DAI }(\mathbf{n}=53)\end{array}$ & $\begin{array}{l}\text { BUD/F ir } \\
\text { FP/S DMI } \\
(\mathbf{n}=58)\end{array}$ & $\begin{array}{l}\text { Visi } \\
(\mathbf{n}=\mathbf{1 1 1})\end{array}$ \\
\hline $\begin{array}{l}\text { Kontroliuo- } \\
\text { jama }\end{array}$ & $30(56,60$ proc. $)$ & $21(36,21$ proc. $)$ & $51(45,94$ proc. $)$ \\
\hline $\begin{array}{l}\text { Iš dalies kon- } \\
\text { troliuojama }\end{array}$ & $17(32,08$ proc. $)$ & $26(44,83$ proc. $)$ & $43(38,74$ proc. $)$ \\
\hline $\begin{array}{l}\text { Nekontroliuo- } \\
\text { jama }\end{array}$ & $6(11,32$ proc. $)$ & $11(18,96$ proc. $)$ & $17(15,32$ proc. $)$ \\
\hline "p $=0,031$ & & & \\
\hline
\end{tabular}

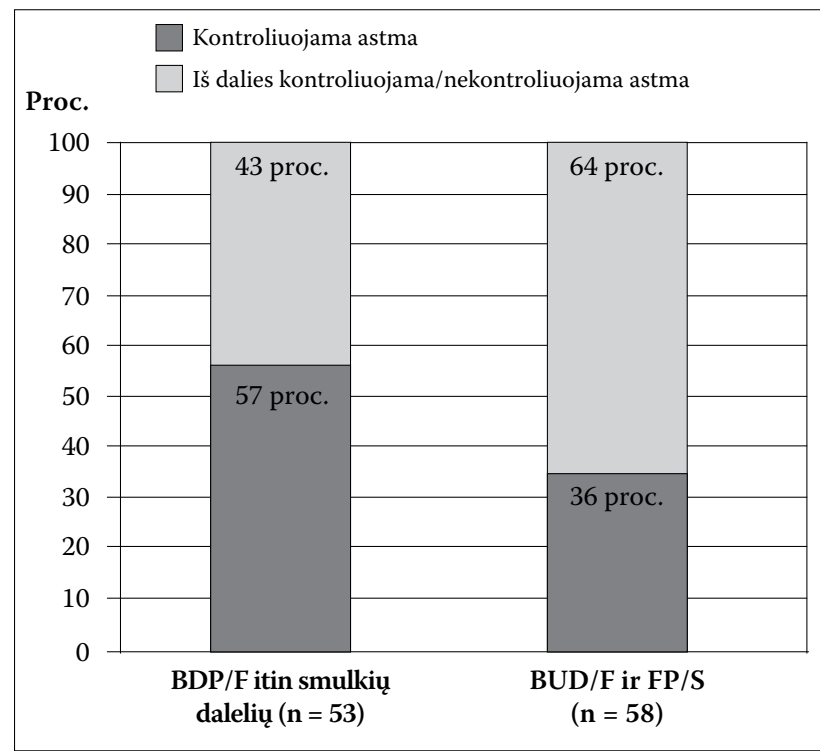

1 pav. Astmos kontrolès lygis skirtingų inhaliatorių grupèse

BDP - beklometazono dipropionatas, BUD - budezonidas, FP - fliutikazono propionatas, $\mathrm{F}$ - formoterolis, $\mathrm{S}$ - salmeterolis.

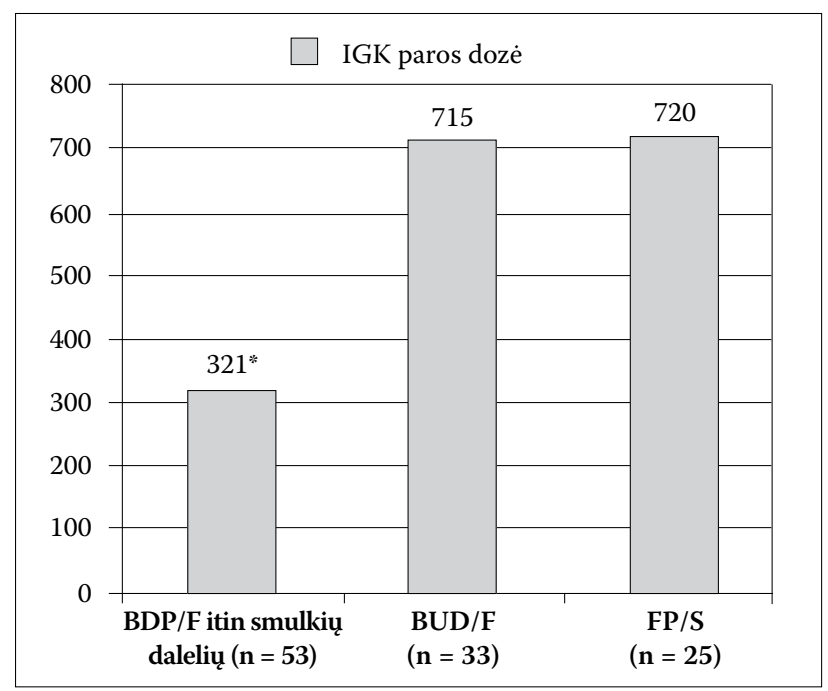

2 pav. Vidutinè IGK paros dozè $(\mu \mathrm{g})$ skirtingose pacientų grupèse " $\mathrm{p}<0,0001 \mathrm{BDP} / \mathrm{F}$ lyginant su BUD/F ir FP/S.

riu gali turèti įtakos tyrimu rezultatams.

Naudojant itin smulkiu daleliụ DAI, pagerejja vaisto kaupimasis ir pasiskirstymas plaučiuose, veiksmingumas mažiau priklauso nuo ịkvejpimo technikos [8]. Be to, tyrimo rezultatai atskleidžia, jog astmos kontrolé 
buvo statistiškai reikšmingai geresnè tų pacientų, kurie naudojo BDP/F itin smulkių dalelių DAI, palyginti su didelių dalelių DMI grupe. BDP/F itin smulkių dalelių DAI grupejje dienos simptomų buvo statistiškai reikšmingai mažiau, taip pat mažiau suvartota ir skubiosios pagalbos vaistų, kas rodo geresnę astmos kontrolę realiame gyvenime.

Sergant astma, uždegimas ir remodeliacija vyksta ne tik stambiuosiuose, bet ir smulkiuosiuose kvèpavimo takuose, todèl ir gydymas turi apimti visą bronchų medi. Vienintelio BDP/F itin smulkios dalelès pasiekia ne tik stambiuosius, bet ir smulkiuosius astma sergančių pacientų kvėpavimo takus [15]. Geresnis vaisto patekimas ị kvėpavimo takus sudaro sąlygas vienodai veiksmingai gydyti uždegimą bei bronchokonstrikciją visame bronchų medyje, prisideda prie geresnès pacientų, gydomų BDP/F itin smulkių dalelių DAI, astmos kontrolès. Kitaip tariant, itin smulkių daleliuc $\mathrm{BDP} / \mathrm{F}$ gali pasiekti bei gydyti ir periferines bronchu medžio dalis, kurių nepasiekia didelių dalelių vaistai, o tai kliniškai svarbu.

Esami ar buvę rūkoriai iš tyrimo nepašalinti, nes jie sudaro didelę dalị astma sergančių pacientų. Rūkančių ir nerūkančių astma sergančių pacientų astmos kontrolè buvo panaši, tačiau nekontroliuojamos astmos dažnumas buvo statistiškai reikšmingai didesnis rūkančiųjų grupèje. Rūkantys astma segantys pacientai dažniausiai ì klinikinius tyrimus neittraukiami, todèl duomenų apie rūkančių ar metusių rūkyti astmos ligonių ligos kontrolę maža.

Pažymètina, jog rezultatų pasiekta vartojant mažesnę IGK paros dozę, o tai rodo, kad gydant BDP/F itin smulkių dalelių DAI garantuojamas didesnis vaisto viename mikrograme veiksmingumas, palyginti su BUD/F ir FP/S. Tai labai svarbus veiksnys, nes dažnai gydymo režimo blogiau laikomasi dèl baiminimosi vartoti gliu- kokortikoidus, o mažesnis kiekis gliukokortikoido viename mikrograme galètų išspręsti šią problemą [28].

Realių sąlygų tyrimo duomenimis, astma buvo kontroliuojama 45,9 proc. pacientų, iš dalies kontroliuojama - 38,7 proc., nekontroliuojama - 15,3 proc. Šie rezultatai atitinka stebejjimo tyrimų, vertinančių astmos kontrolę, duomenis. Klinikinio tyrimo, vykdyto 10 Europos šalių, rezultatai atskleidè, kad, gydant neikkvepiamais gliukokortikoidais, astma buvo tinkamai kontroliuojama 45 proc. pacientu, o gydant ikvepiamais - tik 15 proc. [1].

Šis realių gyvenimo sąlygų tyrimas rodo, jog, gydant IGK ir IVBA sudetiniu vaistu, astmos kontrolè pagal GINA astmos rekomendacijas pasiekiama didelèje astma sergančių pacientų grupejje. Pacientų, gydytų BDP/F itin smulkių dalelių DAI, astmos kontrolè buvo geresnè nei gydytų didelių dalelių BUD/F bei FP/S, išpurškiamais per DMI, o tai skatina manyti, kad inhaliatorių skirtumai bei vaistų formulès gali turèti didelès įtakos klinikinèje praktikoje siekiant geresnių gydymo rezultatų.

\section{ASTHMA CONTROL INPATIENTS RECEIVING INHALED CORTICOSTE- ROID AND LONG-ACTING BETA2-AGONIST FIXED COMBINATIONS. A REAL-LIFE STUDY COMPARING DRY POWDER INHALERS AND A PRESSURIZED METERED DOSE INHALER EXTRAFINE FORMULATION}

\section{EDITA GASIŪNIENE \\ DEPARTMENT OF PULMONOLOGY AND IMMUNOLOGY LITHUANIAN UNIVERSITY OF HEALTH SCIENCE}

Keywords: asthma control, inhaler, beclomethasone propionate, formoterol, extra-fine.

Summary. The real-life study results, which compares asthma control in asthmatic patients treated with dry powder inhalers or a pressurized metered dose inhaler extrafine formulation, are discussed in this article.

\section{LITERATŪRA}

1. Cazzoletti L, Marcon A, Janson C, Corsico A, Jarvis D, Pin I, Accordini S, Almar E, Bugiani M, Carolei A, Cerveri I, Duran-Tauleria E, Gislason D, Gulsvik A, Jõgi R, Marinoni A, Martínez-Moratalla J, Vermeire P, de Marco R: Therapy and Health Economics Group of the European Community Respiratory Health Survey. Asthma control in Europe: a real-world evaluation based on an international population-based study. J Allergy Clin Immunol 2007, 120(6):1360-7.

2. GINA (Global Initiative on Asthma), National Institute of Health, National Heart Lung and Blood Institute: Global Strategy for asthma management and prevention 2009 [http://www.ginasthma.com].

3. Bateman ED, Boushey HA, Bousquet J, Busse WW, Clark TJ, Pauwels RA Pedersen SE, GOAL Investigators Group: Can guideline-defined asthma control be achieved? The Gaining Optimal Asthma ControL study. Am J Respir Crit Care Med 2004, 170(8):836-44.

4. Holgate $\mathrm{S}$, Bisgaard H, Bjermer L, Haahtela T, Haughney J, Horne R, Mclvor A, Palkonen S, Price DB, Thomas M, Valovirta E, Wahn U: The Brussels Declaration: the need for change in asthma management. Eur Respir J 2008, 32(6):1433-42.

5. Rabe KF, Adachi M, Lai CK, Soriano JB, Vermeire PA, Weiss KB, Weiss ST: Worldwide severity and control of asthma in children and adults: the global asthma insights and reality surveys. J Allergy Clin Immunol 2004, 114(1):40-7.

6. Haughney J, Price D, Kaplan A, Chrystyn H, Horne R, May N, Moffat M, Versnel J, Shanahan ER, Hillyer EV, Tunsäter A, Bjermer L: Achieving asthma control in practice: understanding the reasons for poor control. Respir Med 2008, 102(12):1681-93.

7. Lavorini F, Magnan A, Dubus JC, Voshaar T, Corbetta L, Broeders M, Dekh uijzenR,SanchisJ,ViejoJL,BarnesP,CorriganC,LevyM, Crompton GK: Effect of incorrect use of dry powder inhalers on management of patients with asthma. Respir Med 2008, 102(4):593-604.

8. Chrystyn H, Price D: Not all asthma inhalers are the same: factors to consider when prescribing an inhaler. Prim Care Respir J 2009, 18(4):243-9.

9. Dolovich MB, Ahrens RC, Hess DR, Anderson P, Dhand R, Rau JL, Smaldone GC, Guyatt G, American College of Chest Physicians, American College of Asthma, Allergy, and Immunology: Device selection and outcomes of aerosol therapy: Evidence-based guidelines: American College of Chest Physicians/American College of Asthma, Allergy, and Immunology. Chest 2005, 127(1):335-71.

10. Brocklebank D, Ram F, Wright J, Barry P, Cates C, Davies L, Douglas G, Muers M, Smith D, White J: Comparison of the effectiveness of inhaler devices in asthma and chronic obstructive airways disease: a systematic review of the literature. Health Technol Assess 2001, 5(26):1-149.

11. Schulte M, Osseiran K, Betz R, Wencker M, Brand P, Meyer T, Haidl P: Handling of and preferences for available dry powder inhaler systems by patients with asthma and COPD. J Aerosol Med Pulm Drug Deliv 2008, 21(4):321-8.

12. Molimard M, Le Gros V: Impact of patient-related factors on asthma control. J Asthma 2008, 45(2):109-13.

13. Molimard M, Raherison C, Lignot S, Depont F, Abouelfath A, Moore N: Assessment of handling of inhaler devices in real life: an observational study in 3811 patients in primary care. J Aerosol Med 2003, 16(3):249-54. 